\title{
OUGHT AND IS ONCE MORE
}

To be and ought to be; that is the question: - whether 'tis nobler in the mind to suffer the slings and arrows of autonomous obligation, or to take arms against that sea of troubles and by opposing end them? Ay, there's the rub! In Dewey's words,

The problem of restoring integration and cooperation between man's beliefs about the world in which he lives [Ises] and his beliefs about the values and purposes that should direct his conduct [Oughts] is the deepest problem of modern life. [And] It is the problem of any philosophy that is not isolated from that life. ${ }^{1}$

To some it has seemed axiomatic that judgments of obligation and value both can and must be derived from judgments about what is; to others it has seemed equally certain that they neither can be nor need to be in order to be valid since they are intuitively self-evident; still others have thought that they cannot be and yet must be if they are to have any rational basis, concluding that they are arbitrary and irrational. Each of these positions is said by its opponents to puzzle the will and make our enterprises turn awry and lose the name of action, and in this paper I seek to show that all of them are mistaken, at least if they are taken in certain forms. I begin by describing the three positions more fully.

The first position I take to hold that judgments of obligation and value, moral or non-moral, can be inferred logically from premises which are all factual, whether empirical or non-empirical, and that they cannot be regarded as justified unless they can be so inferred from factual premises. In its favor various lines of argument have been or may be advanced, but I shall state only the two that seem to me most apposite.

(1) One, using the parlance of recent philosophy, may be put as follows. Factual statements about what is, was, or will be are often given as reasons 
for judgments of obligation or value. Sometimes they are given as motivating reasons, as in "You should be nice to your neighbors, because then they will be nice to you" or in "Honor thy father and thy mother, that thy days may be long upon the land which the Lord thy God giveth thee." But, sometimes, and this is what counts for the matter in hand, they are given as justifying reasons, as in "You ought to be grateful to your parents, because they have done a great deal for you" or in "Let us love one another, for love is of God." In fact, as is often pointed out, if one says that something is good or ought to be done, then he is in some sense claiming that there are reasons for favoring or for doing it, and it is hard to see how these reasons could be anything but some fact about it, some proposition about what it is like or will lead to. Thus, if A says " $\mathrm{X}$ is good" or "Y is wrong," and B asks "Why?," then A may and must answer with something like "Because it is pleasant" or "Because it will injure someone." In short, an Ought itself virtually claims an Is as its ground. One might even say that to justify a judgment of obligation or value is to derive it from some judgment of fact which is true or taken to be true.

(2) Another line of argument to show that an Ought can be derived from an Is involves the familiar dictum that Ought implies Can. This dictum says that if I cannot do something, then I have no obligation to do it, even if I would otherwise have one. But, if this is so, then, although "I can" does not imply "I ought," "I cannot" does imply "I do not have an obligation." In this sense, a fact about what I cannot do implies something about what obligations I have or do not have. To parody Emerson:

So nigh is Ought-to-Be to Is,

So near is God to man;

When youth protests aloud, "I can't,"

Then Duty says, "You needn't."

In this use the Ought-implies-Can doctrine is employed to show that one does not have a moral obligation in certain cases, but it is assumed that we do have such obligations. But the doctrine also has, since Kant at least, had a more drastic use. It is sometimes argued that moral obligation presupposes that the will is free in a contra-causal sense (and even that there is a God and that the soul is immortal). If this is so, however, 
then, if the will is not free in that sense (or if there is no God or no immortality), there can be no moral obligations at all. Then, from an Is of a certain sort one can infer the falsity or irrelevance of all moral judgments - as has sometimes actually been done. I shall not discuss this line of thought, because I am not convinced that morality does have the particular presuppositions claimed. I suspect, however, that the inference involved would turn out not to be a case of going from an Is alone to a denial of all moral Oughts, i.e. that the notion of moral obligation would appear, not only in its conclusion, but in one of its premises.

The proponents of the second position admit that justifying (as well as motivating) reasons may be given and expected in the case of many at least of our judgments of obligation and value, and that such reasons involve an appeal to a factual premise, empirical, metaphysical, or theological. They insist, however, that, since the statement to be justified is a judgment of obligation or value, containing a term like "good" or "ought," it cannot be justified unless the reasoning offered implicitly or explicitly includes, not only the factual premise mentioned, but also a normative premise about what is valuable or ought to be. An Ought, it is held, can be validly inferred from an Is only in the presence of a more basic Ought taken as a premise; if an Ought or Value term appears in the conclusion then it must also appear in one of the premises, when the premises are made explicit. Thus, when a factual reason is given as a justification for a judgment of obligation or value, as in the examples cited earlier, the reasoning is to be construed either as invalid or as an enthymeme; if it is to be valid, it must be filled out. Filled out in this way, the reasoning involved in the above examples will read, respectively, as follows:

(a) We ought to be grateful to those who benefit us,

(b) Your parents have benefited you,

(c) Therefore, you ought to be grateful to them,

and

(d) We ought to imitate God,

(e) God is love,

(f) Therefore, we ought to love.

Such reasoning, then, is possible if and only if there not only is a factual 
premise like (b) or (e) but also a more basic Ought premise like (a) or (d). These Ought premises themselves may be arrived at by a similar piece of reasoning with a still more basic Ought premise, but ultimately our normative reasoning must end in an appeal to a most basic Ought premise that cannot be established in the same way; it cannot be proved, because it cannot be inferred either from another Ought or from an Is or from a combination of the two - it must, in fact, be regarded as intuitive or selfevident.

Thomists sometimes say that the basic propositions of Natural Law are intuitive or self-evident, as if they were holding this second position, but their critics have often interpreted them as subscribing to the first position and have sometimes taken this second position as a ground for rejecting the doctrine of Natural Law. To my mind the Thomist view is unclear at this point. It is true that Aquinas says that the first precepts of natural law are self-evident, which suggests he is holding the second view. But then he explains this as meaning that anyone who knows the definition of the subject term in such a precept will see that the predicate of the precept is "contained in the notion of the subject." 2 That is, in more modern language, the precept is analytic. And this suggests that he is really maintaining, not the second position, but the first - or, in other words, that he is really not an intuitionist but a naturalist in metaethics, as will be spelled out shortly.

As for the third of the positions indicated at the outset - those who maintain it agree with the proponents of the second that judgments of obligation and value can be justified only by syllogistic reasoning of the sort illustrated, that is, only by appeal to a factual premise plus a more basic judgment of obligation or value. But where the proponents of the second position assert that the most basic judgments of obligation or value are intuitive or self-evident, they deny this to be so, and conclude that such judgments have no rational standing but are simply arbitrary commitments, postulates, or preferences. This third position is nicely illustrated by the opening paragraph of an article by Brian Medlin. He writes,

I believe that it is now pretty generally accepted by professional philosophers that ultimate ethical principles must be arbitrary. One cannot derive conclusions about what should be merely from accounts of what is the case... To arrive at a conclusion in ethics one must have at least one ethical premise. This prem- 
ise, if it be in turn a conclusion, must be the conclusion of an argument containing at least one ethical premise. And so we can go back, indefinitely but not forever. Sooner or later, we must come to at least one ethical premise which is not deduced but baldly asserted. Here we must be a-rational; neither rational nor irrational, for here there is no room for reason even to go wrong. ${ }^{3}$

It seems clear that, for our purposes, the crucial question in thinking about the above three positions is this: can an Ought be logically inferred from an Is without using another Ought as a premise, at least implicitly? ${ }^{4}$ Unless we find a fourth view (as I propose to do), if we say yes, we are committed some form of the first position, and, if we say no, we must choose between the second and third. And if we say no, we must sooner or later take account of the two arguments given in favor of the first position. Before we can say yes, however, we must find some satisfactory reply to the argument based on the "No Ought from an Is" dictum. This argument is a very strong one. Can one who holds the first position meet it in any way? There are three ways in which he might seek to do so. (1) One is by introducing the possibility that Ought may be defined in terms of Is - that "obligation" and "value" can be analyzed into factual or descriptive properties, empirical, metaphysical, or theological. Let us grant that one cannot logically infer "I ought to do A" from "A is commanded by God" or "B is good" from "B is that which all things seek after" without any further ado. But, if one can show that "ought" may be defined as meaning "commanded by God" and "good" as meaning "sought after by all things," then one can validly make the inferences in question. One can go from Is to Ought if one can make out that Good and Ought are to be defined in terms of Is. Spinoza, in effect, saw this when he used definitions of goodness and virtue as premises in proving that "the highest good of the mind is the knowledge of God, and the highest virtue of the mind is to know God," and that "the highest effort of the mind and its highest virtue is to understand things by the third kind of knowledge." 5 One may quarrel with his definitions in this connection, and with his other premises, but one cannot question his logic, which is simply that of geometry. To this extent the "No Ought from an Is" dictum, so confidently assumed by those who take the second and third positions, is false. For the following argument is valid: 
(g) "I ought to do A" means "A is commanded by God"

(h) A is commanded by God

(i) Therefore I ought to do A.

If I accept (g) and (h) then I must accept (i), and there is no problem about this because the term "ought," which appears in the conclusion, is also present in (g).

It is quite possible that this line is the one St. Thomas would take. At any rate, he places the definition of "good" as meaning "that which all things seek after," at the foundation of his entire doctrine of Natural Law. He writes,

Consequently the first principle in the practical reason is one founded on the nature of good, viz. that good is that which all things seek after. Hence this is the first precept of law, that good is to be done and promoted, and evil is to be avoided. All other precepts of the natural law are based upon this ...6

Here he seems simply to assume that one can go from " $\mathrm{X}$ is what all things seek after" to " $\mathrm{X}$ is to be done and promoted." This, as his critics have often pointed out, cannot be done logically without further ado. However, if, besides his definition of "good," he were to define what "is to be done and promoted" as what we do seek after (or would seek after if we knew what we were about), then the logic of his view would be clear and could not be faulted, though one might quarrel with his proposed definitions.

(2) The second line of thought by which one might try to sidestep the "No Ought from an Is" dictum can only be vaguely sketched here. The strength of the dictum lies in the claim that, if one is validly to infer a conclusion from a premise, then there must be no terms in the former that are not in the latter. But, it might be argued, while this may be true of syllogisms and other deductive arguments, there are many inductive inferences in ordinary life, in history, and in science of which it is not true. Such arguments marshal evidence for their conclusions, for which they often claim only probability, and it is not clear that they are "valid" only if there are no terms in their conclusions not already in their premises or only if they are mediated by definitions.

(3) It has been suggested by some writers dealing with our problem that, besides deductive and inductive logic with their respective canons of inference, there may be a third kind of logic for use in reasoning about 
normative matters, a logic consisting of special rules of inference making it possible for an Is to be a reason for an Ought and enabling us to infer validly from a factual premise alone to a conclusion about what is right or good. In effect, each such rule says that a certain fact is a "good reason" (in a non-evaluative sense) for judging that something is good or right, or that, if a certain fact is the case, then one may infer that something is good or right. For instance, one such rule might say that from "X will injure someone" one may infer "I ought not to do X." Then, at least in a society in which this rule is accepted, one may validly reason as follows:

(m) X will injure someone.

(n) Therefore I ought not to do X.

That is, an Ought can be derived from an Is without the help of another Ought as a premise because there is a valid rule of inference that warrants this derivation in certain cases.

It is not possible to deal adequately with these three lines of thought here. For all their plausibility I am still strongly inclined to think that the "No Ought from an Is" dictum is correct if it is taken as saying that no such inference is logically valid. I am not sure line (2) is a sensible one, but even if it is correct, it is hard to see how one can use what it says about inferences about factual matters in everyday life, history, and science to show that it is possible to infer from factual matters to normative ones. Line (3), about which I shall say more later, has had hard going to gain acceptance, and, in fact, no one has yet worked it out satisfactorily (to my mind at least). In any case, there seems to be little difference between taking "if doing X injures someone, then one ought not to do X" as a premise and taking it as a rule of inference. It seems to be equally substantive either way, and leaves us with the question of its justification. Moreover, if there is a difference between taking it as a premise and taking it as a rule of inference, we may still ask why it is to be taken in the latter rather than in the former way. Line (1) seems to me correct as far as it goes. However, whether it goes far enough to show that one can go logically from Is to Ought depends on whether Ought can be satisfactorily defined in terms of Is, and, while I am less impressed than some by the open question argument and the naturalistic fallacy charge so often directed against naturalistic and other definists (metaphysical or theo- 
logical), I nevertheless doubt that judgments of obligation and value can be translated without serious loss into factual or existential ones of whatever sort. In any case, it seems to me that even if, for example, " "good' means 'aimed at by all things" " is a correct definition of what we actually mean by "good," one can only accept it as a definition for use in thinking about and deciding what to do if one already accepts the normative judgment that what is aimed at by all things is good. If this is so, then, in effect, what looks like a definition is tantamount to a value principle, and, if this is so, then we are still left with the problem of its justification and, in particular, of its relation to beliefs about what is.?

Of the three positions originally distinguished, the first says that all Oughts can be directly inferred from some Is or other, and that such inferences are logically valid. The other two insist that no Ought can be logically inferred from any Is except with the help of another Ought taken as a premise, and that the most basic Oughts are therefore logically autonomous with respect to Is (as Plato said, the Good is beyond Being). In these terms, it seems to me, for the reasons indicated, that the second and third positions are correct in maintaining that there is no logical error in refusing to go from any Is whatsoever to any Ought - and that the proponents of the first position cannot rescue themselves by any of the three lines of thought just discussed. Does it follow, as so many have thought, that we must regard basic judgments of obligation or value as either selfevident or arbitrary? Discussing this question J. S. Mill wrote,

Questions of ultimate ends are not amenable to direct proof.... we are not, however, to infer that [the] acceptance or rejection [of an ultimate end] must depend on blind impulse, or arbitrary choice. There is a larger meaning of the word "proof," in which this question is ... amenable to it .... The subject is within the cognizance of the rational faculty; and neither does that faculty deal with it solely in the way of intuition. Considerations may be presented capable of determining the intellect either to give or withhold its assent to the doctrine; and this is equivalent to proof. ${ }^{8}$

Here Mill is claiming that, even if basic normative principles and value judgments cannot be proved by being inferred from true factual premises according to logically valid procedures, and also are not seen to be true 
by intuition, they are still not arbitrary or irrational; it may still be possible to advance factual considerations which make it rational or reasonable, though not logically necessary, to give one's assent to such a principle or value. That is, even if one cannot logically infer an Ought from an Is, one may yet be rational and justified in doing so, and unreasonable otherwise, at least in certain cases. One such case, I take it, is his famous, much-criticized "proof" of hedonism. Here Mill is not pretending that "Pleasure is the good" follows logically from "We all desire pleasure as an end and (basically) only pleasure" (he explicitly says he is not); he is arguing that, since we do all aim at pleasure in this way, it would be absurd or unreasonable, in a "larger" sense than that defined by logic, to deny that pleasure is the good. ${ }^{9}$

Mill seems to me to be on the right track here in suggesting that there is a sense in which one can go from Is to Ought - a sense in which such a process may be rational, reasonable, or justified, even if it is not logical. ${ }^{10}$ Let me try to indicate why by considering two examples. Take first the following bit of conversation:

Him: You ought to go downtown today.

Me: Why?

Him: There is a sale on. You want to buy a new suit, don't you?

In this bit of talk an ought-judgment is made, though not a moral one, and it is defended or justified by the use of two statements of fact, without the use of a normative premise, in a manner that seems entirely natural and reasonable. To state the "practical inference" involved more accurately, it is this:

(a) You want to buy a new suit at a reasonable price.

(b) There is a sale on downtown today.

(c) Therefore you ought to go downtown today.

It might be replied that this inference is justified or reasonable only if another premise is understood, namely,

(d) If you want to buy a new suit at a reasonable price, you ought to adopt the means suited to accomplish that end.

In other words, one needs a further premise with an Ought in it. But, in 
return, I am tempted to say that adducing this premise is a work of logical supererogation; the inference is really quite rational without it. It is not like:

Socrates is a man, Therefore Socrates is mortal,

which does clearly need an additonal premise. One cannot possibly claim that the meaning of "mortal" is such that, if Socrates is a man, then one may correctly go on to say that he is mortal. One has no language-rule connecting "man" and "mortal" and hence one needs a premise that does so.

Von Wright seems to think that the inference in the case cited is justified only if "You ought to ..." is taken to mean "Unless you do, you will fail to ..." i.e. only if "You ought ..." is taken to be a kind of factual statement. But this is because he assumes that a practical inference must be logically valid in order to be justified, and this is just what is in question. It may be that it simply is linguistically appropriate to introduce "ought" into the conclusion even if it does not have von Wright's meaning (viz., you will fail if you don't do ...) and does not appear in any of the premises - just because I am there wanting to buy a new suit cheap (and because the speaker has a pro-attitude toward my doing so). ${ }^{11}$

Consider now a similar example, entirely in the first person: here I am, wanting to buy a new suit at a reasonable price. I read an advertisement of a sale on suits and decide that I should go downtown today if at all possible. One could try to set this practical inference up as follows, as von Wright does: 12

(a) I want to buy a new suit at a reasonable price

(b) There is a suit sale on downtown.

(c) Therefore I ought to go downtown today.

Now, first of all, what I said about the previous example will all apply to this one. But the point I wish to stress is this. If I am actually concluding that I should go downtown today if possible, I must not merely believe that I want to buy a new suit reasonably, I must be wanting a new suit at a reasonable price, and, if I am wanting this, then I may reasonably pass (and only then) from the fact that there is a sale on suits down- 
town to the conclusion that I should go downtown if possible - without any further ado in the way of definitions, additonal Ought premises, rules of inference, etc. - simply because "I should ..." is the appropriate form of expression to use when one has an interest and apprehends facts that are relevant to it. What makes the judgment that I should go downtown today a rational or justifiable one is just such facts as that there is a sale on, plus my desiring to buy a new suit at a bargain price.

What I suggest is that the sort of thing that is true in this rather simple case is true in all cases: i.e. (a) that always, when a piece of practical reasoning seems reasonable and justified, there is present both a factual premise or reason and something that may be called an attitude, interest, or point of view and involves, not just believing a proposition, but being for or against something (it may be an ordinary desire, self-love, "the farmer's point of view," etc.; in the case of moral judgment and reasoning it is "the moral point of view," however that may be defined); (b) that if one has an interest or takes a point of view and then finds or believes that certain relevant facts obtain (that is, facts bearing on that interest or point of view), then one may rationally and justifiably, at least in principle, proceed to a normative conclusion, even if the inference is not strictly according to logical Hoyle (whether it is justified in practice will depend on what the facts appealed to are, whether other interests or points of view are affected, etc.). In fact, while I am less sure of (a) than of (b), I submit that the use of a statement involving some term like "ought" or "good" in a first-hand normative way is appropriate precisely in such a context and only in such a context. Normative discourse just is the appropriate discourse in which to express oneself when one is taking some conative point of view and apprehends facts relevant to it.

What I have said is not intended to deny Mrs. Foot's contention that one cannot well agree that Jones is causing offence by indicating lack of respect and yet deny that Jones is rude - that is, that one may justifiably go from "Jones is causing offence by indicating lack of respect" to "Jones is rude" - even when "Jones is rude" is used evaluatively, as it usually is. ${ }^{13}$ I do want to claim, however, that this inference from an Is to an Ought is justified only if it is made in the presence of a concern that people refrain from doing the sort of thing Jones is doing - the sort of concern that is normally present when people are said to be rude. If I am utterly indifferent, I cannot properly say he is rude. 
If this view of the matter is correct, then there is a sense, though not a strictly logical one, in which one may go from an Is to an Ought in certain contexts, and the context need not consist of another Ought taken as a premise (as the second and third positions allege). So far the first of our original three positions is well-taken. But the other two positions are also well-taken in so far as they maintain that going from an Is to an Ought is not warranted by deductive or inductive logic, nor by the rules of a third logic, nor by the possibility that Ought may be defined in terms of Is. The truth, if I am right, belongs to a fourth position, which preserves what is viable in the other three but rejects their common assumption that a rational inference must be a "logically" valid one. In particular, it should be noticed that this fourth position has most of the virtues claimed for the "third logic" or "good reasons" view, without being open to the same criticisms. (It may even represent what the proponents of that view have been fishing for.)

The similarities and dissimilarities of the three positions I have rejected and the nature of the fourth position I am proposing may be indicated as follows. Consider four propositions:

(1) Judgments of obligation and value (Oughts) are rationally justifiable, objectively valid, etc.

(2) Judgments of obligation and value (Oughts) cannot be logically inferred from factual ones (Ises).

(3) Judgments of obligation and value (Oughts) cannot be rationally justified, objectively valid, etc., unless they can be logically inferred from factual ones (Ises).

(4) Basic judgments of obligation and value are intuitive, selfevident, self-justifying.

The first position affirms (1) and (3) and denies (2) and (4). The second affirms (1), (2) and (4) and denies (3). The third affirms (2) and (3) and denies (1) and (4). The first and second positions agree on (1), the second and third on (2), and the first and third on (3). Only the second position asserts (4). These three positions have this in common: they all assume that there is no reasonable or rationally justified way of going from Is to Ought unless there is a logically valid way of doing so. They all assume; 
even the third-logic people, that every rational or justifiable passage of thought must be warranted by some canon of inference - that the whole business must be captured in the logical machinery of "premises," "rules of inference," and "conclusions," if it is to be a rational or objectively justified transition of mind. What I am suggesting, by way of contrast, is that these assumptions, which are made even by such perceptive moral philosophers as Hampshire and Aiken, are mistaken - that we both do and should regard some inferences or transitions of thought as rational or justified even though the "conclusion" is an Ought, the only "premise" is an Is, and there is no "rule of inference." The resulting fourth position toward which I have been working, then, asserts (1) and (2) and denies (3) and (4).

In objection to this fourth position it may be argued (a) that we do not actually recognize such inferences as those just described as justified or reasonable, (b) that we ought not do so now, even if we have been. The first contention is simply false, as my suit-sale example shows. As for the second - if we do recognize such passages of thought as rational, this fact is, so far, a good reason for continuing to do so, and I do not see that there are any over-riding reasons why we should not. As long as we are shaping our attitudes, points of view, and normative judgments clearheadedly in the light of the fullest relevant knowledge and insight, I see no reason for refusing to call the transitions of thought in question justified or rational. Commenting on C. L. Stevenson's views about validity, H. D. Aiken writes,

Thus, for example, although Professor Charles Stevenson is perhaps more sensitive than any other philosopher to the reality of persuasive definition, he himself falls into it when he refuses, for no reason sanctioned by ordinary language, to accept the possibility that there are any "rational methods" other than those of formal logic and science. Although he freely allows the right of moralists to use, inter alia, what he regards as rational methods when they happen to be appropriate for the purpose of "irrigating" ethical judgments, he nevertheless insists there are no criteria of validity with respect to ethical disputation as such. But why should he fear lest the notion of "validity" be extended so as to include forms of inference which are neither demonstrative nor inductive? As he himself wisely says, "When an inference does not purport to comply with the usual rules, any insistence on its failure to do so is gratuitous." And yet he maintains, to my mind quite unconvincingly, that it is "wholly impracticable and injudicious" (sic) to sanction a definition of validity which extends its usage beyond its applications to logic and to science. Apart from a tenacious desire to reserve 
the emotive meaning of such expressions as "rational" and "valid" for processes of reasoning involved in formal logic and inductive science, what is there to commend Stevenson's position? ${ }^{14}$

Extended to cover the third-logic people as well as Stevenson (and possibly Aiken himself), this seems to me just the right thing to say.

It will help to make the view I am proposing clearer if I comment on another passage from Aiken at this point. Shortly after the one just quoted he goes on to say,

Now I agree once and for all that there are no formal logical rules by means of which one can deduce the ethical proposition " $x$ ought to be done" from any combination of purely factual statements. What I do maintain is that, according to ordinary usage, it is entirely permissible to infer ethical conclusions from factual premises. I should now like to support this contention with some examples. Suppose that it could be shown that a certain act would cause another person unnecessary hardship or suffering; I think that any normal person in our society would regard this as a good, if not sufficient, reason for inferring that, other things remaining equal, the act in question ought not to be performed. Again, suppose it could be shown that the fulfillment of a certain promise would probably cause the person to whom one made it to destroy himself; here also, I think that normal persons would, perhaps reluctantly, conclude from this that the promise ought to be broken. Other examples come to mind.

I conclude from this that, however difficult they may be to specify, there are nevertheless broad principles of relevance or valid inference in moral discourse which enable us, in certain circumstances, to infer ethical conclusions from nonethical premises. But I do not in the least wish to imply by this that the ordinary laws of logic should be amended or broadened. Such laws have no immediate application to the kinds of inference in question. My contention is merely that within the universe of discourse called "moral" or "ethical," certain types of inference are viewed as reasonable, others not. Nor do I wish to say that moral judgments may be "logically derived" from nonethical statements of fact. I think, nothing is gained from such an unnecessary and really misleading extension of the expression "logical derivation." All that needs defending is the thesis that moral reasoning has its own proprieties which, while certainly not written into the starry heavens above, are at least constant and extensive enough to enable the members of a given civilization to distinguish a good reason from a bad one. ${ }^{15}$

Here Aiken is defending the good reasons theory referred to above, though without adopting the notion of a third logic. Now, I agree with him, of course, when he says that there are no formal logical rules by which we may pass from nonethical statements of fact to moral judgments, 
and again when he says that ordinary usage permits us to go from factual premises to ethical conclusions, or that within the universe of discourse called "moral" or "ethical," certain types of inference are viewed as reasonable and others not, and yet again when he argues that we ought not to call such inferences "logical" even in an extended sense. But, while he does not choose to call them rules of a third logic, Aiken does think of these inferences as resting on quasi-logical "proprieties" or "principles of relevance or valid inference" which play a role in moral discourse analogous to that of logical rules of inference rather than to that of premises. This conception he supports with two examples, and I agree that "any normal person in our society" would regard it as reasonable to draw the conclusions indicated in these examples. It is, however, not clear to me that the principles of not causing unnecessary hardship or suffering and of not causing others to commit suicide function in our thinking as rules of inference rather than as premises (if there is a difference). If they are functioning as implicit premises, then these examples are not cases of inferring from factual premises to ethical conclusions, as Aiken thinks they are. But suppose that they are not functioning as premises. It does not follow that they are functioning as "rules of inference." For a third analysis is possible. This is that what carries the "normal member of our society" from the factual premises involved to his ethical conclusion and does so reasonably - is not necessarily any Ought premise, nor any rule of inference, but simply his moral concern for others, his sympathy, or his commitment to the moral point of view. What I wish to suggest, then, is that, when we go from Is to Ought with a sense of reasonableness or justification, we are doing so because we (or someone we are speaking to or of) have an operative concern or interest - not because we have any hidden Ought premises or any special rules of inference that have a quasi-logical status. ${ }^{16}$ I would even like to say that, ultimately, all of our Oughts, even those we sometimes use as premises (or perhaps as rules of inference, if we do so use them) are generated by or accepted in the presence of some concern or interest in confrontation with some apprehension of fact, and that this process may be entirely reasonable even if it is not logical (perhaps even logical norms are generated or accepted in the same way!) Just now, however, I want only to contend that some "inferences" from Is to Ought are justified or rational even if they use no rules of inference and no suppressed Ought premises, just because 
words like "ought" and "good" are linguistically appropriate in such contexts. ${ }^{17}$ And, when I say these "inferences" are justified (other things being equal), I am claiming that any rational being who shares the same concern or point of view will accept them.

It should be observed that this fourth view could be accepted, if not by St. Thomas and his followers, then at least by some near-cousins. Suppose that one wishes to associate judgments of obligation and value with man's "natural tendency" to happiness or self-fulfillment, as J. D. Wild does. ${ }^{18}$ Then one need not define " $X$ is good" or "I ought to do $Y$ " as meaning " $X$ is conducive to the fulfillment of man's natural tendency" or "Y is required for that fulfillment." One need not be a naturalist (or ontological definist) of this sort, as Wild seems to be. One might contend instead that a judgment of obligation or value is an expression of the conatus in question, made in the presence of facts taken to be relevant to it, not an assertion to the effect that one has that conatus or that those facts are relevant to it. Then one would have a view - a non-cognitive one - which would be much like that of the Thomists, but which would be compatible with the one I have been sketching.

However this may be, one could even, if one wished, combine the view sketched with a belief that "good" and "ought" can be satisfactorily defined along such lines as have been variously suggested by St. Thomas, Spinoza, J. D. Wild, S. C. Pepper, R. B. Perry, H. R. Niebuhr, and others. One might then still accept such definitions, but, if I am right, one would have to recognize that underlying one's acceptance of the definitions there is or should be an attitude, interest, or point of view already taken i.e. that the definition is really a crystallization in a certain mode (formal or material) of an attitude, interest, or point of view. The definition would then not necessarily be vitiated by this fact, but the fact would have to be recognized and kept in mind in a way in which it has not usually been by naturalists and other definists. For what would then really mediate the inference from Is to Ought or from Fact to Value would not be the definition but the underlying commitment.

At the opening of Section I, I described two lines of argument for the position that an Ought can and must be derived from an Is. It will be clear 
at once that the view taken in Section III comports well with the first of them. For it agrees that factual premises (Ises) may be reasons for Oughts, and it explains why this is so (as Hume insisted one must). But something must be said about the second - the one using the "Ought implies Can" dictum. Can its point be provided for? This point is that "I cannot" implies "I have no obligation to." The problem is that the use of the word "implies" suggests that there is a logical connection between a statement about what is (cannot be) and one about what obligations we have or do not have. This suggestion I believe to be misleading. The conviction that, if $\mathrm{A}$ is unable to do $\mathrm{B}$, then he has no obligation to do $\mathrm{B}$, and the conviction that if $\mathrm{C}$ was unable to do $\mathrm{D}$, then he is to be excused for not doing $\mathrm{D}$ - these convictions of moral common sense are, in my opinion, not really logical truths. What they mean is something like this: that if $\mathrm{A}$ is unable to do $\mathrm{B}$, then he should not be held to doing it, and that if $\mathrm{C}$ was unable to do $\mathrm{D}$, then he should not be blamed or punished for not doing it. In other words, what appear to be logical truths are really normative principles. They do not give us logical warrants for going from Is to Ought - or rather from Cannot-do to Have-No-Obligation-to-do. Instead they tell us that it is not morally permissible to hold people responsible for what they cannot do, at least if it is not their fault that they cannot do it. In a sense they enable us to go from Cannot-do to Have-No-Obligation-to-do, but they do so only because they are expressions of the moral point of view to which we are already committed (if we accept them at all). Hence, a recognition of such principles does not contravene the view proposed.

This line of thought is supported by another to which I am inclined, namely, that the "can" in "Ought implies can" has a normative meaning. "Can" does, of course, have a factual sense, e.g. in the sentence, "I can jump two feet but I cannot jump 26 feet." But does it have such a purely factual sense in a typical moral case? J. W. Smith and others have suggested that it does not and I think I agree with them. ${ }^{19}$ Suppose that someone is on his way to a meeting that he has an obligation to attend, but breaks his leg on the way (not purposely, of course). He and the rest of us would then regard him as absolved from the obligation to attend the meeting (though possibly not from the obligation to notify us) on the ground that he is unable to make it. But, of course, strictly speaking, as Smith points out, he could make it, even if only by crawling and dragging 
his leg painfully behind him. When we agree that he "can't" make it - or "couldn't have" made it - we are not strictly saying he "can't" or "couldn't have" in the factual sense. We are saying something more like "It would be unreasonable or wrong to expect him to attend the meeting under the circumstances." If this is so, then, in going from "Can' $t$ " to "Has no obligation to," we are not strictly going from a pure Is to a conclusion about an obligation. We are going from something like "It would be wrong to expect ..." to "He has no obligation to ..."

One might reply that our judgment, "It would be wrong to expect ...," is based on a purely factual premise, namely, in our example, that our friend would suffer great pain if he were to attend the meeting, so that we are still going from Is to Ought, or rather Ought not. This is true, but this particular inference may be dealt with in the same way as any argument in which a factual premise is given as a reason for a normative judgment, and so has already been covered by our discussion.

VI

One final remark - in approaching the subject as I have, I have been talking as if there were a fairly clear distinction between the Is and the Ought. Actually, as is well-known, there are all sorts of complexities and difficulties in defining that distinction - witness discussions by $J$. $L$. Austin, John Searle, Dorothy Emmet, and many others. It seems reasonable to hope, however, that my view would survive even if it were to turn out that no clear or workable distinction between the Is and the Ought can be made. Perhaps it would seem more plausible then.

\section{NOTES}

1 John Dewey, The Quest for Certainty (1929), p. 255.

2 See Summa Theologica, I-II, Quest. 94, art. 2, or Basic Writings of Saint Thomas Aquinas, ed. by A. C. Pegis (1945), II, p. 774.

3 "Ultimate Principles and Ethical Egoism," Australasian Journal of Philosophy, 35 (1957), p. 111.

4 Throughout this paper I take Oughts to include judgments about what is desirable, good, or valuable as well as judgments about what is right or obligatory.

5 Ethics, Bk. IV, Prop. xxviii; Bk. V, Prop. Xxv.

Loc. cit.

7 Here cf. my Ethics (1963), pp. 80-85.

8 Utilitarianism, near end of Ch.I. 


\section{OUGHT AND IS ONCE MORE}

9 My interpretation of Epicurus and Mill in "The Naturalistic Fallacy," Mind (48), 1939 , was simply mistaken, as was my interpretation of Hume. For Mill's own rejection of such an interpretation, see loc. cit. and the opening of Ch. IV.

10 "Not logical" does not mean or imply "illogical"; it includes what is "neither logical nor illogical."

11 Cf. G. H. von Wright, "Practical Inference," Philosophical Review, LXXII (1963), pp. 159-179, and Max Black's comments in "The Gap between 'Is' and 'Should',' ibid., LXXVIII (1964), pp. 170 f. Black's own view in this article is very close to the view I am proposing here, but, I think, somewhat less clear. About such views R. M. Hare remarks ("The Promising Game," "Revue Internationale de Philosophie, 70 (1964), p. 398 ) that they set a lower "moral tone" than that of John Searle. In reply I am tempted to quote the old song:

\section{You take the high road, and I'll take the low road.}

But, of course, the real point is that not all "shoulds" and "oughts" are moral, and a general theory, which Searle's is not, must apply to them all. For other indications of my general theory see op. cit., pp. 94-96, and "On Saying the Ethical Thing," Proc. and Addresses of the American Philosophical Association, XXXIX (1966), 21-42.

12 Loc. cit.

13 Philippa Foot, "Moral Arguments," Mind LXVII (1958), 502-513.

14 Reason and Conduct (1962), p. 62.

15 Ibid., pp. $63 \mathrm{f}$.

${ }^{16}$ In the case of institutional Oughts such as Searle discusses in "How to Derive 'Ought' from 'Is'," Phil. Rev., 73 (1964), 43-58, I would say that the inference, if justified at all, is mediated by a commitment to the institution in question and its rules. Cf. A. I. Melden, Rights and Right Conduct (1959) and "Reasons for Action and Matters of Fact,"' Proc. and Add. of Am. Philos. Assoc., XXXV (1961), 45-60; P. Foot, Theories of Ethics (1967), pp. 11f; H. Ofstad and L. Bergstrom, "A note on Searle's Derivation of "Ought' from 'Is"," Inquiry, 8 (1965), pp. 309-314.

17 This does not necessarily imply that "ought" and "good" are definable in "nonethical" terms.

18 Cf. Plato's Modern Enemies and the Theory of Natural Law (1953).

19 Cf. J. W. Smith, "Impossibility and Morals," Mind, LXX (1961). 